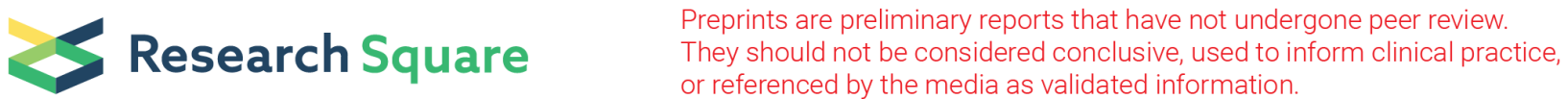 \\ in vitro antibacterial effect of forsterite nanopowder: synthesis and characterization
}

\section{Alexandra Avram}

Babes-Bolyai University Faculty of Chemistry and Chemical Engineering: Universitatea Babes-Bolyai

Facultatea de Chimie si Inginerie Chimica

\section{Sorin Rapuntean}

University of Agricultural Sciences and Veterinary Medicine of Cluj-Napoca Faculty o Veterinary

Medicine: Universitatea de Stiinte Agricole si Medicina Veterinara Cluj-Napoca Facultatea de Medicina Veterinara

\section{Maria Gorea}

Babes-Bolyai University Faculty of Chemistry and Chemical Engineering: Universitatea Babes-Bolyai Facultatea de Chimie si Inginerie Chimica

\section{Gheorghe Tomoaia}

Iuliu Hațieganu University of Medicine and Pharmacy: Universitatea de Medicina si Farmacie Iuliu Hatieganu

\section{Aurora Mocanu}

Babes-Bolyai University Faculty of Chemistry and Chemical Engineering: Universitatea Babes-Bolyai

Facultatea de Chimie si Inginerie Chimica

\section{Ossi Horovitz}

Babes-Bolyai University Faculty of Chemistry and Chemical Engineering: Universitatea Babes-Bolyai Facultatea de Chimie si Inginerie Chimica

\section{Gheorghe Rapuntean}

University of Agricultural Sciences and Veterinary Medicine of Cluj-Napoca Faculty of Veterinary Medicine Universitatea de Stiinte Agricole si Medicina Veterinara Cluj-Napoca Facultatea de Mecina Veterinara

\section{Maria Tomoaia-Cotisel ( $\sim$ mtcotisel.ubbcluj@yahoo.ro )}

Babes-Bolyai University Faculty of Chemistry and Chemical Engineering: Universitatea Babes-Bolyai Facultatea de Chimie si Inginerie Chimica; https://orcid.org/0000-0002-0995-3006

\section{Research Article}

Keywords: Mg2SiO4, forsterite, co-precipitation method, sol-gel method, antibacterial activity, Staphylococcus aureus

Posted Date: February 16th, 2022 
DOI: https://doi.org/10.21203/rs.3.rs-1312061/v1

License: (c) (i) This work is licensed under a Creative Commons Attribution 4.0 International License. Read Full License 


\section{Abstract}

The synthesized forsterite is usually associated with various amounts of periclase (MgO), silicon dioxide $\left(\mathrm{SiO}_{2}\right)$, and enstatite $\left(\mathrm{MgSiO}_{3}\right)$. However, the role of different thermal treatment conditions on the optimal formation of pure forsterite and its antimicrobial activity is not yet deeply evaluated. So, the goal of this study was the preparation, characterization and in vitro antibacterial activity evaluation of forsterite nanopowder ( $\mathrm{FS}, \mathrm{Mg}_{2} \mathrm{SiO}_{4}$ ) obtained by two major methods, namely sol-gel (FSsg) and co-precipitation (FSpp). To assess the best working temperature for the preparation of FSsg and FSpp, the synthesis and thermal treatment conditions were optimized on the basis of thermal gravimetric (TG) and differential scanning calorimetric (DSC) analysis performed on the dried gel and dried co-precipitated solid, respectively. The FSsg and FSpp powders were characterized by X-ray powder diffraction (XRD) indicating a high purity for both FSs and FSpp powders. The morphology of FSsg and FSpp nanopowders was explored by scanning electron microscopy (SEM) coupled with energy dispersive X-ray spectroscopy (EDX) and atomic force microscopy (AFM). In vitro antibacterial activity was investigated using a targeted pathogen, namely Staphylococcus aureus ATCC 6538 P as tested strain by broth dilution technique and inoculations on nutrient agar to highlight the bactericidal inhibitory effect. FSsg nanopowder has no inhibitory capacity, while FSpp produced inhibition, the effect being bactericidal at a concentration of $10 \mathrm{mg} / \mathrm{mL}$. The superior bactericidal activity of FSpp against FSsg is due to variation in the own surface properties, such as specific surface area and nano-regime particle size. The FSpp obtained by co-precipitation method is reported for the first time as a novel bactericidal nanomaterial against Staphylococcus aureus. The nanoparticles, NPs, of FSpp exhibited good intrinsic antibacterial activity, which might potentiate its effect as antibiotic nanocarrier against Staphylococcus aureus. Thus, the novel FSpp may serve as an efficient antibacterial nanomaterial for its biomedical applications in pharmaceutical fields.

\section{Introduction}

During the last few years, a new bioactive silicate, namely forsterite $\left(\mathrm{FS}, \mathrm{Mg}_{2} \mathrm{SiO}_{4}\right)$, was revealed as a suitable bioceramic for bone tissue engineering, due to its good bioactivity and biocompatibility (Naghiu et al. 2013, Choudhary et al. 2017, Choudhary et al. 2020). For instance, forsterite generates fibrous nano hydroxyapatite (HAP) in simulated body fluid, particularly when it is distributed in a polymer matrix and stimulates adhesion and proliferation of osteoblasts in vitro (Furtos et al. 2016). These findings clearly indicate that forsterite can be an excellent candidate for hard tissue engineering applications due to its bioactivity and biocompatibility.

Studies also revealed that forsterite nanopowder is a good carrier for silver nanoparticles, AgNPs (Avram et al. 2020). These findings are comparable to those obtained by using hydroxyapatite, HAP, as carrier of AgNPs (Mocanu et al. 2014) having controlled antibacterial properties.

Removing heavy metal ions by sustainable methods has also been the goal of many studies using mainly hydroxyapatite, HAP, (Ince et al. 2016, Costescu et al. 2014, Zamani et al. 2013, Corami et al. 
2008), bentonite (Hieu et al. 2016, Nehru and Sumathi 2013) and zeolites (Nehru and Sumathi 2013). From our preliminary results, FS nanopowders are also suitable for removal of different water pollutants, like heavy metals similarly to hydroxyapatite, HAP, employing physical interaction such as ion exchange. The removal of natural wastes and biological contaminants is also of great interest (Fernane et al. 2013, Gupta et al. 2011, Narwade 2014, Elwakeel et al. 2018 and Hammad et al. 2020).

Staphylococcus aureus (S. aureus) is a pathogen related to infectious diseases of the eyes, skin and ears (Batista et al. 2017). Staphylococcus aureus is responsible for causing hip joint infections (Choudhary et al. 2018). It was also reported that $S$. aureus is the most predominant strain in samples collected from sea water, being very adaptable (Gabutti et al. 2000). The methicillin-resistant Staphylococcus strain (MRSA) is even more problematic as it has acquired resistance to all known types of penicillin as well as $\beta$-lactam-based antimicrobial drugs (David and Daum 2010). This puts extra strain on the medical system due to the explosion of these types of cases. Methicillin-resistant $S$. aureus genes have been detected in wastewater habitats (Varela and Manaia 2013).

As an alternative, an expensive treatment can be used involving systematic administration of antibiotics, which can cause severe problems in liver and kidneys. Usually, this treatment can also lead to antibioticresistant bacterial strains and often can cause implant failure leading to multiple surgeries. A careless use of a large spectrum of antibiotics can lead to both environmental contamination and the spread of antibiotic-resistant pathogens (Zaha et al. 2020, Bungau et al. 2021). Undoubtedly, the best strategy to avoid bacterial contaminations especially in implants surgery is to develop new biomaterials with intrinsic antibacterial activity.

Over the last decade, studies to tailor the intrinsic antibacterial properties of inorganic materials, mainly by ionic substitution with certain ions or elements in their native structure are in progress. For example, strontium substituted hydroxyapatite, HAP-Sr, has been reported to have antibacterial effects on Lactobacillus, E. coli and S. aureus (Anastasiou et al. 2019), although the $\mathrm{Sr}^{2+}$ effect is disputed in literature. The Zn substituted hydroxyapatite, HAP-Zn, has also been proven to exhibit antibacterial effects on both gram positive (B. subtilis, S. aureus, S. mutans) and gram negative (E. aerogenes, E. coli) bacteria (Chung et al. 2006, Anwar et al. 2016).

Current trend is related to multi-functional hydroxyapatites, as highly biocompatible materials, with wide applications mainly as bone substitutes (Anastasiou et al. 2019, Garbo et al. 2020) or as coatings on metallic implants to enhance the osseointegration and fracture healing (Oltean-Dan et al. 2021). These nanostructured materials can be further used as carriers of AgNPs and antibiotics, to avoid infections in orthopedic surgical applications.

Forsterite has been also studied regarding bone implants (Furtos et al. 2016). Some studies evidenced a potential intrinsic antimicrobial property of forsterite (Choudhary et al. 2017), while others are focused on forsterite-based composites (Saqaei et al. 2016). Another study (Zhu et al. 2020) revealed the photochemically induced antibacterial activity of forsterite scaffolds irradiated with NIR. The antibacterial 
effect might be explained by the ability of $\mathrm{Mg}_{2} \mathrm{SiO}_{4}$ to increase the $\mathrm{pH}$ in the culture medium, which inhibits the development of pathogens. Magnesium ions have the property of decreasing the adhesion of bacteria on surfaces (Demishtein et al. 2019); their presence might lead to the prevention of the biofilm formation.

Due to the high demand of biomaterials for bone regeneration the awareness of discovering new materials enriched in essential physiologic elements, like hydroxyapatite substituted with $\mathrm{Mg}, \mathrm{Zn}, \mathrm{Sr}$ and $\mathrm{Si}$, using innovative environmentally friendly synthesis is increasing day by day (Garbo et al. 2020, Oltean-Dan et al. 2021). As an alternative, forsterite ceramics $\left(\mathrm{Mg}_{2} \mathrm{SiO}_{4}\right)$ represent a new generation of nanomaterials naturally enriched in $\mathrm{Mg}$ and $\mathrm{Si}$, recently discovered to have beneficial effects on osteoblast cells and thereby on bone development. To the best of our knowledge, our previous research (Naghiu et al. 2013) is among the first in this field of research for forsterite ceramics with great potential for biomedical applications. Among the established methods to synthesize powders of forsterite ceramics the chemical co-precipitation, solid-state reaction and sol-gel have been categorized as topranking methods for the synthesis of pure forsterite powder (Douy 2002, Sanosh et al. 2010, Mathur et al. 2018). Generally, the synthesized forsterite is associated with periclase ( $\mathrm{MgO})$, silicon dioxide $\left(\mathrm{SiO}_{2}\right)$, and enstatite $\left(\mathrm{MgSiO}_{3}\right)$ (Douy 2002, Choudhary et al. 2017). But the role of different thermal treatment conditions on the formation of forsterite, and its antimicrobial activity is not yet deeply evaluated. So, in this work, two methods, sol-gel and co-precipitation, are used and optimized for the preparation of pure forsterite, starting with the same precursors, like $\mathrm{Mg}\left(\mathrm{NO}_{3}\right)_{2}$ and tetraethylorthosilicate (TEOS). Clearly, the diversification of synthesis conditions as well as preparation methods causes the structural properties of resulting forsterite to differ greatly. To the best of our knowledge, the synthesis conditions and the processing of raw materials used so far to synthesize forsterite have never been subjected to deep analysis of the correlation between resulting forsterite nanoparticle size and intrinsic antimicrobial activity.

Accordingly, in the present work, we focused on using the same starting materials, $\mathrm{Mg}\left(\mathrm{NO}_{3}\right)_{2}$ and tetraethylorthosilicate, TEOS, as in our previous work (Avram et al. 2020), but the synthesis conditions, preparation methods and the thermal treatment conditions are established differently to facilitate a better control on particle size during the synthesis and calcination process. Our purpose was to examine whether a synthesis procedure might determine the size of forsterite nanoparticles leading to different properties, like revealing the intrinsic antimicrobial activity of synthesized forsterite. Then, the obtained FS powders are characterized by XRD, SEM-EDX and AFM. Further, the effect of these FS powders on the Staphylococcus aureus 6538P strain (ATCC) is explored by broth dilution method and inoculations on nutrient agar.

\section{Experimental Part}

\section{Materials and synthesis methods}


Forsterite nanopowder was synthesized through two methods, namely sol-gel (FSsg) and co-precipitation (FSpp).

FSsg nanopowder was prepared by a sol-gel method using magnesium nitrate hexahydrate $\left(\mathrm{Mg}\left(\mathrm{NO}_{3}\right)_{2}\right.$. $6 \mathrm{H}_{2} \mathrm{O}, 99.5 \%$ purity, Merck, Darmstadt, Germany) and tetraethyl orthosilicate (TEOS, $\mathrm{Si}\left(\mathrm{OC}_{2} \mathrm{H}_{5}\right)_{4}, 99 \%$ purity Merck, Darmstadt, Germany ) as precursors and following a Mg:Si = 2:1 molar ratio for the forsterite formula. TEOS was added to an aqueous solution of magnesium nitrate, followed by the addition of a sucrose solution ( $10 \mathrm{~g} / 25 \mathrm{~mL}$ water for $1 \mathrm{~g}$ FS final after combustion). The mixture was homogenized and brought to a pH of 1 using $65 \%$ nitric acid (p.a. Merck, Darmstadt, Germany). Gel maturation was done at room temperature for $24 \mathrm{~h}$, followed by a drying process at $110^{\circ} \mathrm{C}$ for $4 \mathrm{~h}$. Finally, the dried gel was calcined at $900^{\circ} \mathrm{C}$ for $2 \mathrm{~h}$, with a heating rate of $10^{\circ} \mathrm{C} / \mathrm{min}$.

FSpp was synthesized using the same precursors and molar ratio described above. TEOS was added to an aqueous solution of magnesium nitrate according to the stoichiometric ratio. The mixture was vigorously stirred for $2 \mathrm{~h}$ on a magnetic stirrer at $1500 \mathrm{rpm}$. Ammonium hydroxide $\left(\mathrm{NH}_{4} \mathrm{OH}, 25 \%\right.$, p.a. Merck, Darmstadt, Germany) was added to the stirring solution until a pH of 12 was reached to avoid $\mathrm{MgO}$ formation and precipitation has begun. The dispersion containing the co-precipitate was continuously stirred for $30 \mathrm{~min}$. The white co-precipitate was separated from supernatant by filtration and washed with ultrapure water for many times to remove the remaining $\mathrm{NH}_{4} \mathrm{OH}$. Then, the co-precipitated solid was dried at $110^{\circ} \mathrm{C}$ for $4 \mathrm{~h}$ in a laboratory oven. Finally, the co-precipitated solid was calcined at $900{ }^{\circ} \mathrm{C}$ for $2 \mathrm{~h}$, using a heating rate similar to that one used for FSsg.

\section{Characterization methods}

The synthesis and thermal treatment conditions for FSsg and FSpp were optimized on the basis of thermal analysis (TG and DSC) performed on the dried gel and dried co-precipitated solid, respectively, using a SDTQ600 TA Instruments New Castle, USA, with a thermal analyzer equipped with alumina crucibles. The analysis was carried out in air with a heating rate of $10^{\circ} \mathrm{C} / \mathrm{min}$ for a temperature interval of $30-1000{ }^{\circ} \mathrm{C}$.

Pure stoichiometric forsterite, FSsg and FSpp, powders obtained after calcination at $900{ }^{\circ} \mathrm{C}$ for $2 \mathrm{~h}$, were characterized by $X R D, S E M-E D X$ and $A F M$ prior to antibacterial investigation.

X-ray diffraction (XRD) spectra of the synthesized powders were obtained by using a Bruker D8 Advance diffractometer (Cu Ka1 of $1.5406 \AA$, operated at $35 \mathrm{kV}$ and $40 \mathrm{~mA}$ ), Karlsruhe, Germany. The spectra were collected on a $2 \theta\left(10^{\circ}-70^{\circ}\right)$ with a $0.02 \%$ sec step.

Field emission scanning, transmission electron microscope, STEM, Hitachi HD-2700 Tokyo, Japan, operated at a maximum acceleration voltage of $200 \mathrm{kV}$ was used for morphology investigation of FS powders. SEM images coupled with energy dispersive X-ray spectroscopy, EDX spectra, were used for chemical investigation of FS powders. 
Atomic force microscopy (AFM) images were obtained by using an AFM JEOL 4210 Tokyo, Japan, equipment operated in tapping mode, using silicon nitride tip cantilevers, having resonance frequency in the range of $200-300 \mathrm{kHz}$ and a spring constant of $17.5 \mathrm{~N} / \mathrm{m}$.

Both types of forsterites, FSsg and FSpp, nanopowders were subjected to ultrasonication process using a ultrasonic processor Sonics Vibra-Cell, model VCX 750 (Sonics \& Material Inc., Newtown, CT, USA) in deionized water at room temperature for $3 \mathrm{~h}$, and afterwards deposited by adsorption on glass plates as a thin layer for AFM investigation.

In vitro antibacterial testing of the effects of FSsg and FSpp was performed using a Staphylococcus aureus strain (ATCC 6538P). The forsterite samples (in powder form) were named as follows: 1 for (FSsg) samples, forsterite obtained through the sol-gel method, calcined $900^{\circ} \mathrm{C}$ for $2 \mathrm{~h}$ (i.e., 4 samples of $10 \mathrm{mg}$ FSs each); and $\mathbf{2}$ for (FSpp) samples, forsterite obtained through the co-precipitation method, calcined at $900{ }^{\circ} \mathrm{C}$ for $2 \mathrm{~h}$ ( 4 samples of $10 \mathrm{mg}$ FSpp each). Testing of antimicrobial activity was performed by the method of dilutions in sterile nutrient broth (Merck, Darmstadt, Germany); to assess the inhibitory effect of bacteria growth (presence/absence; bactericidal/bacteriostatic) inoculations were made on Petri dishes with Mueller Hinton sterile nutrient agar (Merck, Darmstadt, Germany). For the dilution of each forsterite, FSsg or FSpp, in nutrient broth, two series of 5 test tubes, per each FS, of 100/10 mm were prepared: one series for product 1 (FSsg) and the second one for product 2 (FSpp), of which 4 tubes are for diluting forsterite and the fifth tube is considered for the control sample. Both series were identically tested, using the same procedure. The dilution scheme was as follows: firstly, the nutrient broth was distributed in tubes in the following quantities: $1 \mathrm{~mL}$ in tube 1 and $0.5 \mathrm{~mL}$ in tube 5 (the control), and $0.5 \mathrm{~mL}$ in tubes 2, 3 and 4 (see, Scheme 1). Then, in tube 1, $10 \mathrm{mg}$ of forsterite powder was added, resulting a mixture of $10 \mathrm{mg} \mathrm{FS} / \mathrm{mL}$ of broth which was homogenized by stirring; from tube $1,0.5$ $\mathrm{mL}$ dispersion was distributed into test tube 2, obtaining a dispersion of $5 \mathrm{mg} \mathrm{FS} / \mathrm{mL}$, which was homogenized; after, $0.5 \mathrm{~mL}$ from tube 2 was passed into tube 3 , obtaining $2.5 \mathrm{mg} \mathrm{FS} / \mathrm{mL}$, which was homogenized, and $0.5 \mathrm{~mL}$ was passed into test tube 4 obtaining a dispersion of $1.25 \mathrm{mg} \mathrm{FS} / \mathrm{mL}$; after homogenization from tube 4 , about $0.5 \mathrm{ml}$ of dispersion was removed. After completion of dilutions, all 5 test tubes of each series, corresponding to FSsg and separately to FSpp, were inoculated with $10 \mu \mathrm{L}$ culture ( $0.5 \mathrm{McF}$ arland density standard $/ 1 \times 10^{8} \mathrm{CFU}$ ) of Staphylococcus aureus strain ATCC 6538P (see Scheme 1). Subsequently, the tubes were placed in an incubator at $37^{\circ} \mathrm{C}$ for $24 \mathrm{~h}$, after which the interpretation was made, assessing the turbidity and sediment in each tube.

Because the forsterite powder does not dissolve in the nutrient broth, the suspended FS particles or sediment, respectively, do not allow an appreciation of the inhibitory effect in the broth tubes. To verify that an inhibitory effect occurred, each tube with the corresponding dilution was inoculated on a Petri dish with Mueller Hinton agar, divided into 5 sectors (4 sectors, each one for every tube with forsterite dilution and the 5 th sector for the control tube). The plate was incubated at $37^{\circ} \mathrm{C}$, for $24 \mathrm{~h}$, after which it was interpreted. Each measurement was repeated for three times

\section{Results And Discussion}


To prepare FSsg and FSpp, the precursors were wet mixed, processed and then dried, obtaining dried gel and dried precipitated powder, respectively. The minimum calcination temperature requested to induce the formation of crystalline forsterite itself, either FSsg or FSpp, was determined by TG and DSC analysis performed on dried concentrated mixtures, respectively (Douy 2002, Sanosh et al. 2010, Mathur et al. 2018).-

Figs 1 and 2 show the TG and DSC curves for the two samples, dried concentrated gel for FSsg and dried precipitated powder for FSpp, to evaluate the associated thermal treatment with the formation of forsterite crystals.

The thermal treatment, revealed in Fig. 1, was performed on the dried gel obtained following the hydrolysis and condensation processes that take place in solution after homogenization and heating. The thermal diagram shows a broad endothermic peak of low intensity at relatively low temperatures, up to $233^{\circ} \mathrm{C}$ which is due to the removal of adsorbed water from dried concentrated gel. The weight loss is $22.69 \%$. Up to $500{ }^{\circ} \mathrm{C}$, the oxidation of organic components occurs in the gel structure with the formation of volatile compounds that leave the sample. These processes are represented by two exothermic peaks, one with lower intensity, between $233^{\circ} \mathrm{C}$ and $381^{\circ} \mathrm{C}$ and a second one between $381^{\circ} \mathrm{C}$ and $465^{\circ} \mathrm{C}$ with high intensity. The mass loss that occurs is significant, $11.19 \%$ for the first process and $38.17 \%$ for the second one. The slow mass loss that is observed between $465^{\circ} \mathrm{C}$ and $1000{ }^{\circ} \mathrm{C}$ is due to the gradual elimination of the residue of volatile compounds formed by the oxidation of organic components ( 2.78 $\%)$. The total weight loss is $74.83 \%$ and is specific to this sol-gel method, due to the use of a large amount of chelating agents. At around $833^{\circ} \mathrm{C}$, an exothermic peak of low intensity is observed; see the inset in Fig. 1, without a significant mass loss that can be attributed to the formation of the new crystalline forsterite phase, namely FSsg. Therefore, the minimum calcination temperature of about 833 ${ }^{\circ} \mathrm{C}$ is determined as the necessary temperature to induce the formation of crystalline FSsg powder. In consequence, the dried concentrated gel was further calcined at $900^{\circ} \mathrm{C}$ for $2 \mathrm{~h}$, using a heating rate of 10 ${ }^{\circ} \mathrm{C} / \mathrm{min}$.

Fig. 2 presents the TG curve and heat flow as DSC curve during heating of co-precipitated hydroxide powder. Two endothermic peaks can be observed at lower temperatures, up to $360^{\circ} \mathrm{C}$ that can be attributed to adsorbed water and residual ammonium nitrate removal from the co-precipitated powder. These successive endothermic effects are associated with the mass loss of $16.08 \%$ and $16.19 \%$, respectively. Another two sequential endothermic processes take place at higher temperatures and can be attributed to the dehydroxylation of the intermediate precipitated products containing - $\mathrm{MgOH}$ groups and -SiOH groups, that can be further converted into oxides upon heating (Zampiva et al 2017).

Dehydroxylation of $-\mathrm{MgOH}$ groups takes place between $360-582{ }^{\circ} \mathrm{C}$ with a continuous mass loss of $10.11 \%$ and that of $-\mathrm{SiOH}$ groups takes place on a temperature interval that goes from $582-800{ }^{\circ} \mathrm{C}$ and has a mass loss of $9.70 \%$. The mass loss between $800{ }^{\circ} \mathrm{C}$ and $1000^{\circ} \mathrm{C}$ is due to the gradual elimination 
of the remaining of volatile compounds formed by the oxidation of organic components (3.71\%).The overall mass loss for the co-precipitated powder is $55.79 \%$. An exothermic effect without a large mass variation can be observed on the DSC curve at around $847^{\circ} \mathrm{C}$ (see inset in Fig. 2). This effect might be attributed to the formation of crystalline forsterite phase, noted FSpp. Consequently, the dried coprecipitated powder was calcined at $900^{\circ} \mathrm{C}$ for $2 \mathrm{~h}$, using a heating rate of $10^{\circ} \mathrm{C} / \mathrm{min}$.

\section{$X$-ray powder diffraction}

The X-ray powder diffraction (XRD) patterns are presented in Fig. 3 for forsterite nanopowder obtained through both sol-gel and co-precipitation methods. The XRD patterns show the presence of a wellcrystallized phase, characterized by well-defined narrow peaks, for the two FSsg and FSpp samples.

For FSsg, the synthetic forsterite (PDF 83-0542) was identified as the only detectable phase, suggesting that the heat treatment and general synthesis conditions are optimal. Well-defined peaks are also found for FSpp, forsterite (PDF 83-0542), indicating the absence of a second phase such as $\mathrm{MgO}$ or $\mathrm{MgSiO}_{3}$, which are usually present in forsterite conventional synthesis. Although FSpp is the main predominant phase (around $98 \%$ ), some traces of quartz (PDF 83-0542) and stishovite (PDF 86-2333) can be found.

Certainly, both FSsg and FSpp are synthetic forsterite of high purity, with crystallinity of $67 \%$ and $52 \%$, respectively. They crystallize in the orthorhombic system, space group Pbnm with cell parameters: $a=0.4747 \mathrm{~nm} ; b=1.020 \mathrm{~nm}$ and $c=0.5990 \mathrm{~nm}$, for FSsg, and cell parameters: $a=0.4754 \mathrm{~nm} ; b=1.020$; $\mathrm{c}=0.5980 \mathrm{~nm}$, for FSpp. The crystallite size is about $41.8 \mathrm{~nm}$ for FSsg and around $20.3 \mathrm{~nm}$ for FSpp.

\section{Scanning electron microscopy (SEM)}

Fig. 4 shows the SEM image (Fig. 4a) coupled with EDX analysis (Fig 4b) for FSsg and Fig. 5, the SEM image (Fig. 5a) coupled with EDX analysis (Fig. 5b) for FSpp. A difference in morphology can be observed between the two forsterite samples indicating that the synthesis method influences the size and distribution of particles. The FSpp sample has a more compact appearance, the particles being smaller and having a more pronounced tendency to agglomerate. FSsg particles are better individualized, having larger dimensions when compared to FSpp. However, it can be observed that in the case of both samples the nanoparticles have a homogeneous granulometric (particle-size) distribution in a narrow dimensional range, evenly distributed, a fact highlighted by the histograms in Fig. 6.

\section{Chemical analysis of forsterite nanoparticles}

SEM coupled with EDX is used for the chemical analysis of FS samples (FSsg and FSpp). EDX spectra confirm the presence of $\mathrm{Mg}$, Si and $\mathrm{O}$, the constituent elements of forsterite $\left(\mathrm{Mg}_{2} \mathrm{SiO}_{4}\right)$. The compositions given by these spectra are reasonably close to the expected values for both FSsg and FSpp (Table 1): $\mathrm{Si} / \mathrm{Mg}$ mole ratio is $\mathbf{0 . 5}$, or for weight ratio is 0.578 for theoretical values. For instance, from the spectrum in Fig. $5 \mathrm{~b}$, the $\mathrm{Si} / \mathrm{Mg}$ ratio is found to be 0.52 for mole ratio, respectively 0.60 for weight ratio. The Si/Mg 
ratio is closer to the theoretical one in the case of FSpp which suggests a better homogeneity of the initial mixture.

Table 1 Chemical composition of FSpp and FSsg

\begin{tabular}{|lllllll|}
\hline \multirow{2}{*}{ Elements } & \multicolumn{2}{l}{ Weight ratio } & \multicolumn{5}{c|}{ Mole ratio } \\
\cline { 2 - 7 } & Theoretical & FSpp & FSsg & Theoretical & FSpp & FSsg \\
\hline Si/Mg & 0.578 & 0.60 & 0.693 & 0.5 & 0.52 & 0.60 \\
O/Mg & 1.316 & 1.03 & 1.66 & 2 & 1.57 & 2.52 \\
\hline
\end{tabular}

Histograms of particles size distribution were obtained for the two kinds of forsterite samples, FSsg and FSpp, by measuring the diameters of over a hundred particles on SEM images and are presented in Fig. 6.

The mean diameters $(\bar{d}$ ) and standard deviation (SD) values for the two samples are $\bar{d}=23.8 \mathrm{~nm}$; SD $=5.6 \mathrm{~nm}$, for FSpp, and $\bar{d}=40.1 \mathrm{~nm} ; \mathrm{SD}=7.1 \mathrm{~nm}$, for FSsg. From the one-way ANOVA test, at the 0.05 level, the means are significantly different. Forsterite obtained by the precipitation method contains smaller particles and their size distribution is rather narrower.

\section{Atomic force microscopy (AFM)}

The FSsg sample exhibits the formation of a smooth layer of very well adsorbed nanoparticles. Its characteristic 2D topography image is presented in Fig. 7a highlighting nanoparticles with well individualized rounded shapes and without a tendency to coalesce. This is due in part to the $3 \mathrm{~h}$ ultrasonication time of the dispersion before deposition and the short adsorption time that prevented the formation of clusters on the glass surface. The phase image, Fig. 7b, shows very distinctly the forsterite nanoparticles which are brown in color. This is further evidence of the good individualization of the forsterite nanoparticles synthesized by the sol-gel method. The amplitude image, Fig. 7c, shows that the scan took place in optimal conditions and there are no assembly defects on the surface of the FSsg layer. The smooth appearance with well-individualized FSsg nanoparticles is very well seen in the 3D image, Fig. 7d.

The cross-section profile captures three successive FSsg nanoparticles on the deposited film on glass support. The rounded shape and the narrow diameter of around $37 \pm 4 \mathrm{~nm}$ can be observed.

The AFM images for the FSpp sample are presented in Fig. 8, having a slightly porous structure.

The formation of a rather porous layer of fine FSpp nanoparticles adsorbed from aqueous dispersion on glass plate. They are well individualized and appear very close to each other. In the case of Fig. 8, the film is less dense, and the nanoparticles seem to be better seen. This is more visible in the 3D image in Fig. $8 \mathrm{~d}$. It can be noticed that the deposited film is quite smooth. The nanoparticles appear well individualized in the phase image, Fig 8b, having a brown color while the free space between them has a yellow hue. 
The amplitude image, Fig. 8c, shows that the FSpp film was adsorbed uniformly and is free of defects. The profile in Fig. 8 e shows a sequence of 3 adjacent nanoparticles of FSpp. The profile shows a diameter of $21 \pm 2 \mathrm{~nm}$.

The size of FSpp nanoparticles is smaller than the size of FSsg nanoparticles in substantial agreement with the size of these NPs visualized in SEM images, and with the data obtained from XRD.

Definitely, the significant difference in size between the two types of forsterite particles has been revealed by XRD, SEM and AFM. Usually, it is assumed that the particles are spherical without porosity, and in turn the specific surface area, SSA, can be estimated (Brantley and Mellott 2000) by the relation:

$\operatorname{SSA}=6 /(\mathrm{d} \rho)(1)$

where $d$ is the average diameter of nanoparticles and $\rho$ is the density of forsterite, namely about 3.3 $\mathrm{g} / \mathrm{cm}^{3}$ (Lloyd and Bailey 1975, Zhang et al. 2010). With the measured diameters, it was found a surface area of about $45 \mathrm{~m}^{2} / \mathrm{g}$ for FSsg and around $83 \mathrm{~m}^{2} / \mathrm{g}$ for FSpp.

\section{Antibacterial testing}

The efficacy of FSsg (noted 1) and FSpp (noted 2) against $S$. aureus was studied using broth dilution technique (Scheme 1) since the FS samples are insoluble in organic solvents and consequently their diffusion in agar is limited.

Because the forsterite powder does not dissolve in the nutrient broth, the suspended FS particles or sediment, respectively, do not allow an appreciation of the inhibitory effect in the broth tubes. Firstly, to verify that an inhibitory effect occurred, about $10 \mu \mathrm{L}$ dispersion from each tube (see Scheme 1 ) with the corresponding dilution was inoculated on a Petri dish with Mueller-Hinton agar, previously divided into 5 sectors (i.e., 4 sectors, each one for every tube with forsterite dilution and the $5^{\text {th }}$ sector for the control tube). The plate was incubated at $37^{\circ} \mathrm{C}$, for $24 \mathrm{~h}$, after which it was interpreted.

In sample 1 (FSsg) no inhibitory effect was found at any dilution of forsterite, observing the development of colonies in all the corresponding triangles of the Petri dish in which they were inoculated (positions 1 , 2, 3 and 4), including in the triangle corresponding to the control tube (position 5) (Fig. 9a).

In sample 2 (FSpp) an inhibitory effect was found only in tube 1 (10 mg solid forsterite and $1 \mathrm{~mL}$ nutrient broth), noting the absence of colonies in the corresponding triangle (position 1). At the other dilutions, respectively $5 \mathrm{mg}, 2.5 \mathrm{mg}$ and $1.25 \mathrm{mg}$, no inhibitory effect appears, observing the development of colonies in all the corresponding triangles (positions 2, 3 and 4), including the triangle corresponding to the control tubes (position 5) (Fig. 9b).

The plates shown in Fig. 9 were kept under observation for another 5 days (in wet chambers), without any changes compared to the initial appearance. 
Identical results were obtained after re-testing of samples 1 and 2, thus demonstrating that FSpp induces an inhibitory effect at the first dilution (10 mg FSpp in $1 \mathrm{~mL}$ nutrient broth) and has no inhibitory effect at lower tested dilutions.

Secondly, from the primary tubes with 1 (FSsg), $10 \mathrm{mg}$ in $1 \mathrm{~mL}$ nutrient broth, and 2 (FSpp), $10 \mathrm{mg}$ in 1 $\mathrm{mL}$ nutrient broth, kept for 48 hours at room temperature, see Scheme 1, the inoculation was performed on a new plate, and inoculating was performed on a Petri dish with Muller Hinton agar, divided in two halves: the left side 1 (FSsg) and the right side 2 (FSpp). Then, the plate was incubated at $37^{\circ} \mathrm{C}$ for 24 hours. Upon interpretation, there was a lack of inhibitory effect on 1 (FSsg), with colony development, Fig. 10 (part 1), and inhibitory effect on 2 (FSpp), with lack of colony development, and the nutrient culture medium remains sterile, Fig. 10 (part 2).

Thirdly, from the primary tubes (used to inoculate the agar plate), respectively 1 (FSsg) with $10 \mathrm{mg}$ FSsg/ $1 \mathrm{~mL}$ nutrient broth and 2 (FSpp) with $10 \mathrm{mg} \mathrm{FSpp} / 1 \mathrm{~mL}$ nutrient broth, after $72 \mathrm{~h}$ from initial preparation, and maintained at laboratory temperature, inoculations $(10 \mu \mathrm{L})$ were made in tubes with nutrient broth $(5 \mathrm{~mL})$, followed by incubation at $37^{\circ} \mathrm{C}$ for $24 \mathrm{~h}$.

On interpretation, it was found that in the tube containing sample 1 (FSsg), there was intense turbidity and easy to homogenize sediment, because of staphylococcal bacterial growth, which means that there was no inhibitory effect. At the control made by the Gram stain, staphylococci with characteristic morphology were stained. In the tube containing sample 2 (FSpp) it was found that the inoculated broth remained clear, being sterile, which meant that the sample had an inhibitory effect on bacteria growth (Fig. 11).

To check if the inhibition of the staphylococci was bactericidal, from tubes 1 (FSsg) and 2 (FSpp), contact time $72 \mathrm{~h}$, inoculations were performed on a Petri dish with Mueller Hinton agar, divided in two halves, which were inoculated: left side for sample 1 (FSsg) and right side - sample 2 (FSpp). The plate was placed in the incubator at $37^{\circ} \mathrm{C}$ for $24 \mathrm{~h}$, after which the result was evaluated.

It was found that sample 1 (FSsg) has no inhibitory effect, with typical Staphylococcus colonies developing in the corresponding area (left side of the plate). In sample 2 (FSpp) was found that it caused inhibition of staphylococcal growth in the corresponding area (right side of the plate), without the development of colonies, the nutrient medium remaining sterile. The plate was kept under observation for a further 3 days (wet chamber), without any changes to the original appearance. It could be deduced that the inhibitory effect produced by 2 (FSpp) is evidently bactericidal.

To see if the inhibitory effect is correlated with the contact time, both powder samples, 1 (FSsg) of $10 \mathrm{mg}$ FSsg, and 2 (FSpp) of $10 \mathrm{mg}$ FSpp, were each hydrated as follows: $10 \mathrm{mg}$ solid product and $1 \mathrm{~mL}$ saline solution (B Braun Ag Germany) and left in contact for $24 \mathrm{~h}$, the tubes being shaken several times on a vortex mixer. After $24 \mathrm{~h}, 10 \mu \mathrm{L}$ (calibrated loop) of liquid culture of Staphylococcus aureus (strain 6538P ATCC), at a dilution of 0.5 according to McFarland standard, was introduced into the tubes (for both samples). From these tubes, inoculations were made on a Petri dish with Mueller Hinton agar, divided into 
5 triangular sectors, after the following contact times (minutes): $5 \rrbracket, 10 \rrbracket, 15 \rrbracket, 30 \rrbracket$ and $60 \rrbracket$. The plates were incubated and evaluated after $24 \mathrm{~h}$.

In the plate with sample 1 (FSsg) it was found that colonies were developed in all the corresponding triangles, which meant that no inhibitory effect occurred at any of the contact times (Fig. 13a). In the plate with sample 2 (FSpp) was also found that colonies were developed in all the corresponding triangles (Fig. 13b), being more abundant at the contact times 5, 10 and $15 \mathrm{~min}$, and sparse at contact time of $30 \mathrm{~min}$ and $60 \mathrm{~min}$.

In order to verify whether the inhibition on staphylococci still occurs after a time exceeding 60 minutes, the tubes with saline dispersions were kept at laboratory temperature for another $24 \mathrm{~h}$. From these tubes, inoculations were performed on a Petri dish with the Mueller Hinton medium, divided into two halves, which were inoculated by streaking the left side product 1 (FSsg) and the right side product 2 (FSpp). After, the new plate was incubated at $37^{\circ} \mathrm{C}$ for $24 \mathrm{~h}$, after which the interpretation was performed.

Sample 1 (FSsg) was found to have no inhibitory effect, and typical Staphylococcus colonies were developed in the corresponding area (Fig. 14, left side). In sample 2 (FSpp), the inhibition of Staphylococcus development in the corresponding area (Fig. 14, right side) was observed, without the appearance of colonies, the culture medium remaining sterile. The plate was kept under observation for a further 5 days, without any changes to the initial appearance. It has been confirmed that the sample 2 (FSpp) has bactericidal effect on staphylococci.

In this study the FS samples were subjected to a complex antimicrobial testing process on S. aureus. Testing of the samples, FSsg and FSpp, by the method of dilutions in nutrient broth, showed that the inhibitory effect against the $S$. aureus strain was found only for the FSpp, at a dilution of $10 \mathrm{mg} / \mathrm{mL}$. Inoculation on Petri plates with Mueller Hinton agar confirmed that FSpp has bactericidal inhibitory effect against $S$. aureus. Inoculation in tubes with nutrient broth also confirmed that FSpp has inhibitory effect (broth remained clear, being sterile). In relation to the different contact times, 5, 10, 15, 30 and 60 minutes, FSpp samples do not have an inhibitory effect on $S$. aureus growth in the control Petri dish. Extending the contact time to $24 \mathrm{~h}$, the FSpp powder produced inhibition, the effect being bactericidal on S. aureus.

In this study, the FSpp obtained by precipitation method is discovered for the first time as a novel bactericidal nanomaterial against $S$. aureus. This bactericidal activity of FSpp nanoparticles is rather superior to previous reports where FS particles were unable to inhibit the bacterial growth at concentrations from 25 to $200 \mathrm{mg} / \mathrm{mL}$ (Saqaei et al. 2016).

Another study working with forsterite synthesized by a sol-gel combustion method found an inhibition effect on S. aureus at $0.5 \mathrm{mg} / \mathrm{mL}$ broth dilution (Choudhary et al. 2018). An earlier study, on the same forsterite but using agar diffusion, evidenced an effect starting at $100 \mathrm{mg} / \mathrm{mL}$ (Choudhary et al. 2017). On the other hand, a forsterite prepared through mechanical activation was reported without any antibacterial effect on the $S$. aureus at broth concentrations of $25 \mathrm{mg} / \mathrm{mL}$ (Saqaei et al. 2016). The 
discrepancy in the antimicrobial activity data existing in literature could be explained by the influence of the synthesis method and conditions on the characteristics of the final FS product (Zhu et al. 2020).

Our results for bactericidal effect of FSpp nanopowder against $S$. aureus are found to be reliable at a broth dilution of $10 \mathrm{mg} / \mathrm{mL}$. Further, inoculation on Petri dishes with Mueller Hinton agar, confirmed that FSpp has bactericidal inhibitory effect (lack of colony development on the culture plate). Moreover, inoculation in nutrient broth also confirmed that FSpp product has inhibitory effect (broth remained clear, being sterile).

\section{Mechanism of FSpp antibacterial activity}

The mechanism by which FSpp nanoparticles produce an inhibitory effect on the tested Staphylococcus aureus strain might be explained by assuming the adsorption of nanoparticles on the cell wall of bacteria. In this hypothesis, it is possible to consider FSpp particles adsorbed and agglomerated on the surface of bacteria, causing mechanical damage to the cell wall and cytoplasmic membrane, disrupting their barrier function, especially the transfer of nutrients through the plasma membrane. Such a mode of action was found on some bacteria (e.g., Staphylococcus aureus and Escherichia coli) by electron microscopy showing that the bacteria treated with various composites containing forsterite were covered with layers of composite particles, and thus, the inhibitory effect was more pronounced against $S$. aureus, depending on the composite that had a higher ratio of forsterite (Choudhary et al. 2020).

The agglomeration of FSpp nanopaticles around the surface of Staphylococcus aureus may inhibit the bacterial membrane processes resulting in cell death by leakage of genetic materials, proteins and minerals (Li et al. 2008).

FSpp powder possesses the smallest nanoparticles and has a specific surface area of almost twice that corresponding to FSsg. Consequently, it is to be admitted that the released $\mathrm{Mg}^{2+}$ amount from FSpp in the broth is higher than that from FSsg during the incubation period. In turn the released $\mathrm{Mg}^{2+}$ ions can increase significantly the broth $\mathrm{pH}$ by ionic exchange with the $\mathrm{H}^{+}$ions from broth to alkaline $\mathrm{pH}$.

The $\mathrm{Mg}^{2+}$ ions are found to have a binding capacity to S. aureus membrane (Xie and Yang 2016) which varied with $\mathrm{pH}$ of medium. Specifically $\mathrm{Mg}^{2}{ }^{+}$ions interact with cardiolipin (Som et al. 2009), which is a major lipid component in S. aureus membrane (Short and White 1971, Tsai et al. 2011), and form complexes (Cutinelli and Galdiero 1967, Rand and Sengupta 1972) and thus, disrupt S. aureus membrane (Li et al. 2008) and destabilize membrane processes and finally kill bacteria. Clearly, FSpp has the potential to arrest the bacterial growth causing cytotoxic activity and bacterial apoptosis.

It is also mentioned that changing the $\mathrm{pH}$ of the environment, in the sense of increasing its value, also plays an important role in antibacterial effect of FS. This change in $\mathrm{pH}$ is considered the most important activity for the bactericidal action of forsterite. There is research indicating an increase in $\mathrm{pH}$ in culture media, from 7.2 in the initial stage of the broth to 8.93 in the broth with nano-powders (Saqaei et al. 2016), respectively from 6.8 to 7.5, after $24 \mathrm{~h}$ of incubation (Choudhary et al. 2018). Subsequently, it is 
believed that an increase in $\mathrm{pH}$ determines the denaturation of proteins and several cytoplasmic components of cells, which can precipitate in the environment, resulting in a decrease in the bacteria population.

In relation to different contact times $(5,10,15,30$ and $60 \mathrm{~min})$, it was found that both samples (FSsg and FSpp), do not have inhibitory capacity at the mentioned times, but by prolonging the contact time to $24 \mathrm{~h}$ and by hydrating the sample, it was found that the FSpp induced inhibition (absence of colony development), the effect being bactericidal, and the FSsg product did not have inhibitory capacity (colony of bacteria was developed).

Furthermore, FSpp nanopowder having intrinsic antimicrobial property is appropriate for bacteria removal through biosorption, particularly for Staphylococcus aureus, which might be present in the surface water. In addition, from our preliminary results, both forsterite FSsg and FSpp nanopowders are suitable for removal of different water pollutants, like heavy metal ions similarly to hydroxyapatite, employing physical interaction such as ion exchange. Moreover, the FSpp powder can better monitor the water pollutants due to predominantly smaller size of NPs, and consequently a higher specific surface area of its constitutive NPs compared to FSsg.

These findings suggest that suitable synthesis conditions can assist in fabrication of pure FSpp powder leading to specific surface properties of its nanoparticles of controlled size having a superior antimicrobial activity against Staphylococcus aureus. Thus, FSpp powder can serve as coatings on metallic implants decreasing the risk of implant infections during bone surgery.

In summary, this study suggests that $\mathrm{Mg}^{2+}$ ions may have implications in targeted eradication of $S$. aureus pathogen, being membrane active against $S$. aureus and destabilizing $S$. aureus membrane and killing bacteria.

\section{Conclusion}

This study provides two methods, sol-gel and co-precipitation, for the synthesis of FSsg and FSpp nanoparticles, respectively, of high purity. The FSpp obtained by co-precipitation method is reported for the first time as a novel bactericidal nanomaterial against Staphylococcus aureus, at a concentration of $10 \mathrm{mg} / \mathrm{mL}$. This bactericidal activity of FSpp nanoparticles is rather superior to previous reports on FS prepared by different methods, like sol-gel method. Thus, FSpp exhibits a rather strong intrinsic antibacterial property against Staphylococcus aureus. Accordingly, FSpp may serve as an effective antibacterial nanomaterial for its biomedical applications in pharmaceutical fields. Both FSpp and FSsg nanopowders can be also used as carriers for silver nanoparticles and for antibiotics as coatings on metallic orthopedic implants against infections caused by Staphylococcus aureus.

\section{Declarations}

- Ethics approval and consent to participate: Not applicable 
- Consent for publication: Not applicable

- Availability of data and materials: Not applicable

- Competing interests: The authors declare that they do not have any competing interests

- Funding: This work was supported by grants of the Ministry of Research, Innovation and Digitization, CNCS/CCCDI-UEFISCDI, project number 186 and 481, within PNCDI III.

- Authors' contributions: All authors: Alexandra Avram, Sorin Rapuntean, Maria Gorea, Gheorghe Tomoaia, Aurora Mocanu, Ossi Horovitz, Gheorghe Rapuntean, and Maria Tomoaia-Cotisel have equal contributions. All authors mentioned above have read and approved the final manuscript.

\section{Acknowledgments}

This work was supported by grants of the Ministry of Research, Innovation and Digitization, CNCS/CCCD/UEFISCDI, project number 186 and 481, within PNCDI III.

\section{Author contributions}

All authors contributed equally.

\section{Disclosure}

The authors report no conflicts of interest in the present work.

\section{References}

1. Anastasiou AD, Nerantzaki M, Gounari E, Duggal MS, Giannoudis PV, Jha A, Bikiaris D (2019) Antibacterial properties and regenerative potential of $\mathrm{Sr}^{2+}$ and $\mathrm{Ce}^{3+}$ doped fluorapatites; a potential solution for periimplantitis. Sci Rep 9:14469 (11 pages). https://doi.org/10.1038/s41598-019-5091644

2. Anwar A, Akbar S, Sadiqa A, Kazmi M (2016) Novel continuous flow synthesis, characterization and antibacterial studies of nanoscale zinc substituted hydroxyapatite bioceramics. Inorganica Chim Acta 453:16-22 https://doi.org/10.1016/j.ica.2016.07.041

3. Avram A, Gorea M, Rapuntean S, Mocanu A, Paltinean GA, Varhely C Jr, Petean I, Horovitz O, Tomoaia-Cotisel M (2020) In-vitro antibacterial activity of novel nanostructuread composites based on forsterite and silver nanoparticles. Rev Chim (Bucharest) 71(1):13-21. https://doi.org/10.37358/RC.20.1.7805

4. Batista AHM, Moreira ACD, de Carvalho RM, Sales GWP, Nogueira PCN, Grangeiro TB, Medeiros SC, Silveira ER, Nogueira NAP (2017) Antimicrobial effects of violacein against Planktonic cells and biofilms of Staphylococcus aureus. Molecules 22:1543. https://doi.org/10.3390/molecules22101534

5. Brantley SL, Mellott NP (2000) Surface area and porosity of primary silicate minerals. Am Mineral 85(11-12):1767-1783. https://doi.org/10.2138/am-2000-11-1220 
6. Bungau S, Tit DM, Behl T, Aleya L, Zaha DC (2021) Aspects of excessive antibiotic consumption and environmental influences correlated with the occurrence of resistance to antimicrobial agents. Curr Opin Environ Sci Health 19:100224. https://doi.org/10.1016/j.coesh.2020.10.012

7. Choudhary R, Manohar P, Vecstaudza J, Yanez-Gascon MJ, Perez Sanchez H, Nachimuthu R, Locs J, Swamiappan S (2017) Preparation of nanocrystalline forsterite by combustion of different fuels and their comparative in-vitro bioactivity, dissolution behaviour and antibacterial studies. Mater Sci Eng C 77:811-822. https://doi.org/10.1016/j.msec.2017.03.308

8. Choudhary R, Chatterjee A, Venkatraman SK, Koppala S, Abraham J, Swamiappan S (2018) Antibacterial forsterite $\left(\mathrm{Mg}_{2} \mathrm{SiO}_{4}\right)$ scaffold: A promising bioceramic for load bearing applications. Bioact Mater 3(3):218-224 https:// doi.org/10.1016/j.bioactmat.2018.03.003

9. Choudhary R, Venkatraman SK, Bulygina I, Chatterjee A, Abraham J, Senatov F, Kaloshkin S, Ilyasov A, Abakumov M, Knyazeva M, Kukui D, Walther F, Swamiappan S (2020) Impact of forsterite addition on mechanical and biological properties of composites. J Asian Ceram Soc 8(4):1051-1065. https://doi.org/10.1080/21870764.2020.1807695

10. Chung R-J, Hsieh M-F, Huang C-W, Perng L-H, Wen H-W, Chin T-S (2006) Antimicrobial effects and human gingival biocompatibility of hydroxyapatite sol-gel coatings. Chin J Biomed Mater Res B Appl Biomater 76:169-178. https://doi.org/10.1002/jbm.b.303655

11. Corami A, Mignardi S, Ferrini V (2008) Cadmium removal from single- and multi-metal $(\mathrm{Cd}+\mathrm{Pb}+\mathrm{Zn}+\mathrm{Cu})$ solutions by sorption on hydroxyapatite. J Colloid Interface Sci 317:402-408. https://doi.org/10.1016/j.jcis.2007.09.075

12. Costescu A, Andronescu E, Vasile BS, Trusca R, Le Coustumer P, Barna ES, Iconaru SL, MontelicaHeino M, Ciobanu CS (2014) Synthesis and characterization of dextran coated hydroxyapatite for environmental applications. U Politeh Buch Sci Bull Ser B 76(4):71-80

13. Cutinelli C, Galdiero F (1967) lon-binding properties of the cell wall of Staphylococcus aureus. J Bacteriol 93(6):2022-2023. https://doi.org/0.1128/jb.93.6.2022-2023.1967

14. David MZ, Daum RS (2010) Community-associated methicillin-resistant Staphylococcus aureus: epidemiology and clinical consequences of an emerging epidemic. Clin Microbiol Rev 23(3):616687. https://doi.org/10.1128/cmr.00081-09

15. Demishtein K, Reifen R, Shemesh M (2019) Antimicrobial properties of magnesium open opportunities to develop healthier food. Nutrients 11(10):2363 (8 pages). https://doi.org/10.3390/nu11102363

16. Douy $A(2002)$ Aqueous syntheses of forsterite $\left(\mathrm{Mg}_{2} \mathrm{SiO}_{4}\right)$ and enstatite $\left(\mathrm{MgSiO}_{3}\right)$. J Solgel Sci Technol 24:221-228

17. Elwakeel KZ, El-Liethy MA, Ahmed MS, Ezzat SM, Kamel MM (2018) Facile synthesis of magnetic disinfectant immobilized with silver ions for water pathogenic microorganism's deactivation. Environ Sci Pollut Res 25:22797-22809. https://doi.org/10.1007/s11356-018-2071-6

18. Fernane F, Boudia B, Saouli H (2013) Interactions between calcium phosphate and heavy metal ions in aqueous solution. MATEC Web of Conferences, 5:1-5. 
https://doi.org/10.1051/matecconf/20130504034

19. Furtos G, Naghiu MA, Declercq H, Gorea M, Prejmerean C, Pana O, Tomoaia-Cotisel M (2016) Nano forsterite biocomposites for medical applications: Mechanical properties and bioactivity. Biomed Mater Res Part B Appl Biomater 104B(7):1290-1301. https://doi.org/10.1002/jbm.b.33396

20. Gabutti G, de Donno A, Bagordo F, Montagna MT (2000) Comparative survival of faecal and human contaminants and use of Staphylococcus aureus as an effective indicator of human pollution. Mar Pollut Bull 40(8):697-700. https://doi.org/10.1016/S0025-326X(00)00007-2

21. Garbo C, Locs J, D’Este M, Demazeau G, Mocanu A, Roman C, Horovitz O, Tomoaia-Cotisel M (2020) Advanced Mg, Zn, Sr, Si multi-substituted hydroxyapatites for bone regeneration. Int J Nanomed 15:1037-1058. https://doi.org/10.2147/IJN.S226630

22. Gupta N, Kushawaha AK, Chattopadhyaya MC (2011) Adsorption of cobalt (II) from aqueous solution onto hydroxyapatite/zeolite composite. Adv Mat Lett 2(4):309-312. https://doi.org/10.5185/amlett.indias.201

23. Hammad ABA, El Hanwary AM, Hemdan BA, Abia ALK (2020) Nanoceramics and novel functionalized silicate-based magnetic nanocomposites as substitutional disinfectants for water and wastewater purification. Environ Sci Pollut Res 27:26668-26680

24. Hieu DTM, Tran PTT, Ton AK, Le MV (2016) A novel method for the fabrication of granular hydroxyapatite-bentonite composite adsorbents for the removal of $\mathrm{Pb}^{2+}$ from an aqueous solution. $\mathrm{J}$ Environ Sci Eng B 5:371-378. https://doi.org/10.17265/2162-5263/2016.07.008

25. Ince OK, Ince M, Kraaslan NM, Yonten V (2016) Optimization of cadmium removal from water by hydroxyapatite using experimental design methodology. Anal Lett 49(15):2513-2524. https://doi.org/10.1080/00032719.2016.1151022

26. Li Q, Mahendra S, Lyon DY, Brunet L, Liga MV, Li D, Alvarez PJJ (2008) Antimicrobial nanomaterials for water disinfection and microbial control: potential applications and implications. Water Res 42:4591-4602. https://doi.org/10.1016/j.watres.2008.08.015

27. Lloyd FE, Bailey DK (1975) Light element metasomatism of the continental mantle: the evidence and the consequences. In: Ahrens LH, Dawson JB, Duncan AR, Erlank AJ (eds) Physics and chemistry of the earth, vol 9. Pergamon Press, Oxford · New York · Toronto · Sydney · Paris · Frankfurt, p 412

28. Mathur L, Hossain SKS, Majhi MR, Roy PK (2018) Synthesis of nano-crystalline forsterite $\left(\mathrm{Mg}_{2} \mathrm{SiO}_{4}\right)$ powder from biomass rice husk silica by solid-state route. Bol Soc Esp Ceram V 57:112-118

29. Mocanu A, Furtos G, Rapuntean S, Horovitz O, Flore C, Garbo C, Danisteanu A, Rapuntean Gh, Prejmerean C, Tomoaia-Cotisel M (2014) Synthesis characterization and antimicrobial effects of composites based on multi-substituted hydroxyapatite and silver nanoparticles. Appl Surf Sci 298:225-235 https://doi.org/10.1016/j.apsusc.2014.01.166

30. Naghiu MA, Gorea M, Mutch E, Kristaly F, Tomoaia-Cotisel M (2013) Forsterite nanopowder: structural characterization and biocompatibility evaluation. J Mater Sci Technol 29(7):628-632. https://doi.org/10.1016/j.jmst.2013.04.007 
31. Narwade VN, Mahabole MP, Bogle KA, Khaimar RS (2014) Waste water treatment by nanoceramics: Removal of lead particles. Int J Eng Sci Innov Technol 3(3):324-328

32. Nehru M, Sumathi S (2013) Removal of cadmium (II) and nickel (II) ions by copper substituted hydroxyapatite. Int J Appl Eng Res 8(19):2179-2181

33. Oltean-Dan D, Dogaru G-B, Jianu E-M, Riga S, Tomoaia-Cotisel M, Mocanu A, Barbu-Tudoran L, Tomoaia Gh (2021) Biomimetic composite coatings for activation of titanium implant surfaces: methodological approach and in vivo enhanced osseointegration. Micromachines 12:1325. https://doi.org/10.3390/mi12111352

34. Rand RR, Sengupta S (1972) Cardiolipin forms hexagonal structures with divalent cations. Biochim Biophys Acta 255:484-492

35. Sanosh KP, Balakhrishnan A, Francis L, Kim TN (2010) Sol-gel synthesis of forsterite nanopowders with narrow particle size distribution. J Alloy Compd 495:113-115

36. Saqaei M, Fathi M, Edris H, Mortazavi V, Hosseini N (2016) Effects of adding forsterite bioceramic on in vitro activity and antibacterial properties of bioactive glass-forsterite nanocomposite powders. Adv Powder Technol 27:1922-1932. https://doi.org/10.1016/j.apt.2016.06.023

37. Short SA, White DC (1971) Metabolism of phosphatidylglycerol, lysylphosphatidylglycerol, and cardiolipin of Staphylococcus aureus. J Bacteriol 108(1):219-226

38. Som A, Yang L, Wong GCL, Tew GN (2009) Divalent metal ion triggered activity of a synthetic antimicrobial in cardiolipin membranes. J Am Chem Soc 131(42):15102-15103

39. Tsai M, Ohniwa RL, Kato Y, Takeshita SL, Ohta T, Saito S, Hayashi H, Morikawa K (2011) Staphylococcus aureus requires cardiolipin for survival under conditions of high salinity. Microbiol 11:13 (12 pages)

40. Varela AR, Manaia CM (2013) Human health implications of clinically relevant bacteria in wastewater habitats. Environ Sci Pollut Res 20:3550-3569. https://doi.org/10.1007/s11356-0131594-0

41. Xie Y, Yang $L$ (2016) Calcium and magnesium ions are membrane-active against stationary-phase Staphylococcus aureus with high specificity. Sci Rep 6:20628

42. Zaha DC, Bungau S, Uivarosan D, Tit DM, Maghiar TA, Maghiar O, Pantis C, Fratila O, Rus M, Vesa CM (2020) Antibiotic consumption and microbiological epidemiology in surgery departments: results from a single study center. Antibiotics 9:81. https://doi.org/10.3390/antibiotics9020081

43. Zamani S, Salahi E, Mobasherpour I (2013) Removal of nickel from aqueous solution by nano hydroxyapatite originated from Persian Gulf corals. Can Chem Trans 1(3):173-190. https://doi.org/10.13179/canchemtrans.2013.01.03.0033

44. Zampiva RYS, Acauan LH, dos Santos LM, Ribeiro de Castro RH, Kopp Alves A, Perez Bergmann C (2017) Nanoscale synthesis of single phase forsterite by reverse strike co-precipitation and its high optical and mechanical properties. Ceram Int 43(16):16225-16231. https://doi.org/10.1016/j.ceramint.2017.08.201 
45. Zhang Y, Ni H, Chen Y (2010) Diffusion data in silicate melts. Rev Mineral Geochem 72:311-408. https://doi.org/10.2138/rmg.2010.72.8

46. Zhu T, Zhu M, Zhu Y (2020) Fabrication of forsterite scaffolds with photothermal-induced antibacterial activity by 3D printing and polymer-derived ceramics strategy. Ceram Int 46:1360713614. https://doi.org/10.1016/j.ceramint.2020.02.146

\section{Figures}

\section{Figure 1}

The weight as a function of temperature, TG curve, and heat flow vs temperature, DSC curve, for dried concentrated gel.

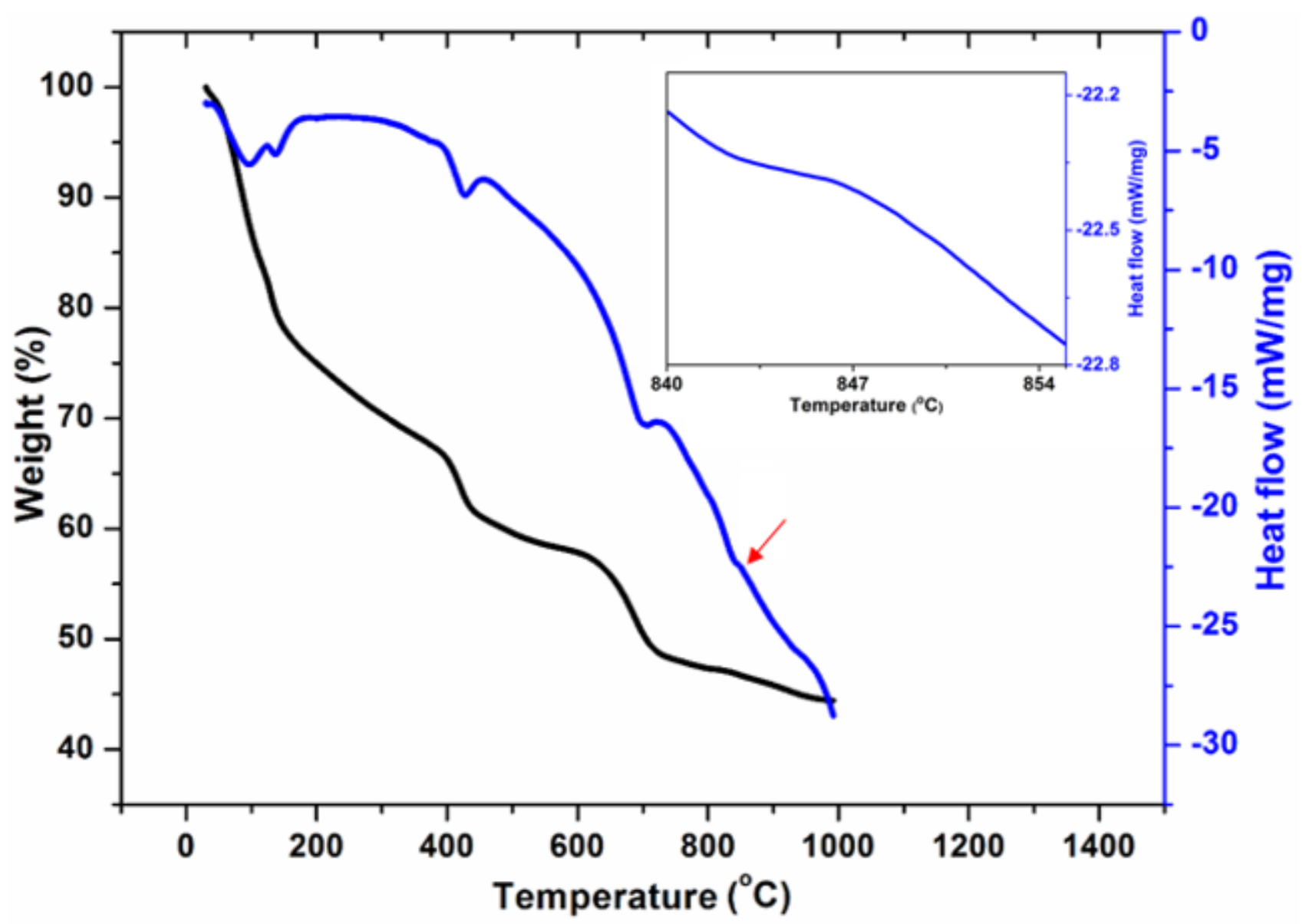

Figure 2

TG and DSC curves for dried co-precipitated powder. 


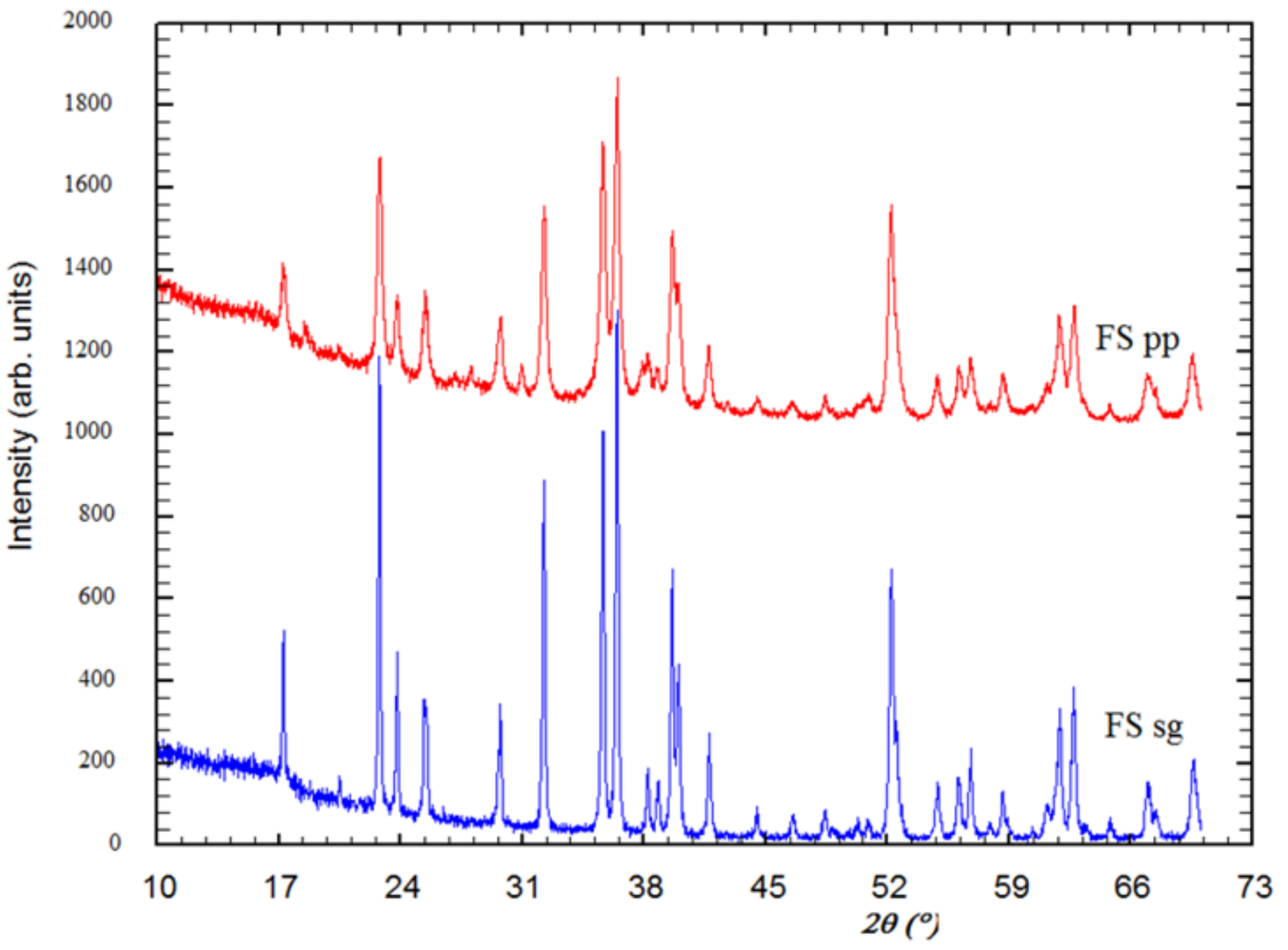

Figure 3

X-ray powder diffraction spectra for FSsg and FSpp.

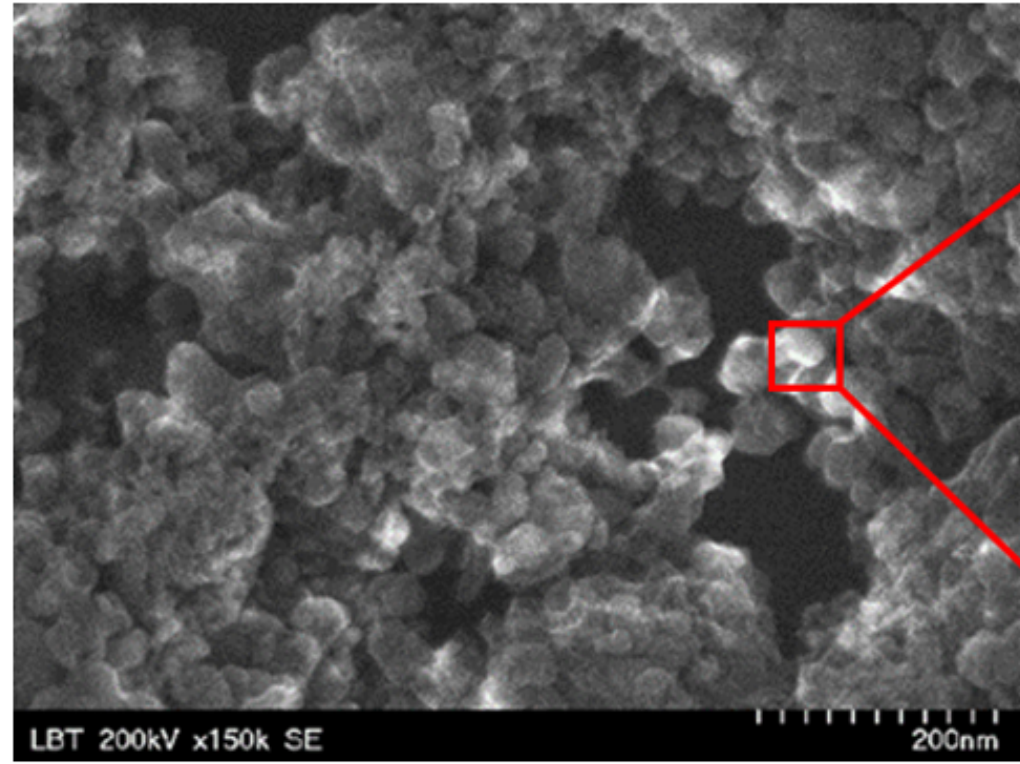

a

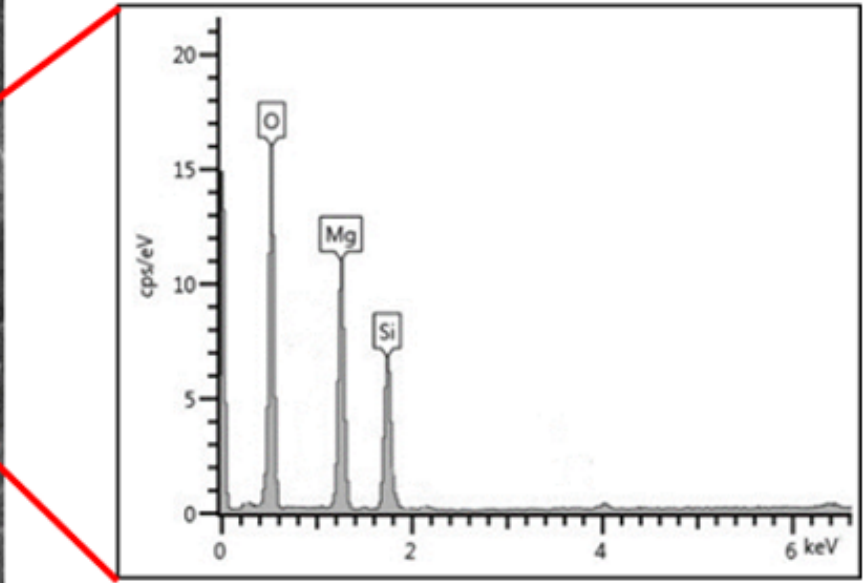

$\mathrm{b}$ 
Figure 4

SEM image for FSsg (a), with $200 \mathrm{~nm}$ scale bar, coupled with EDX (b).

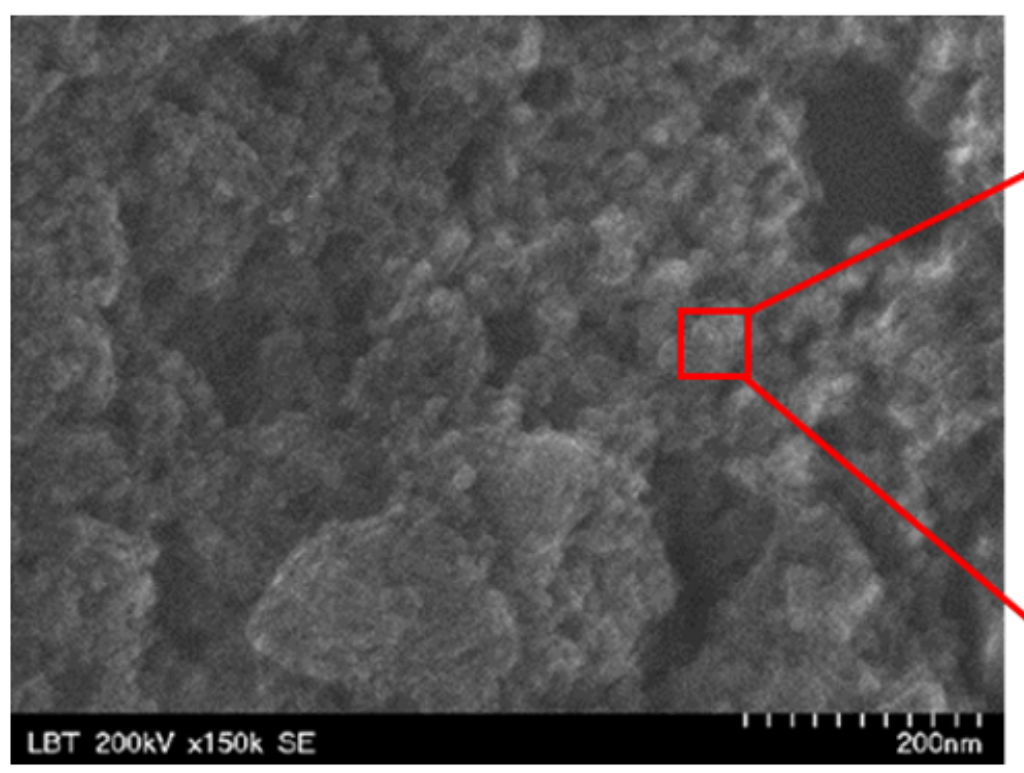

a

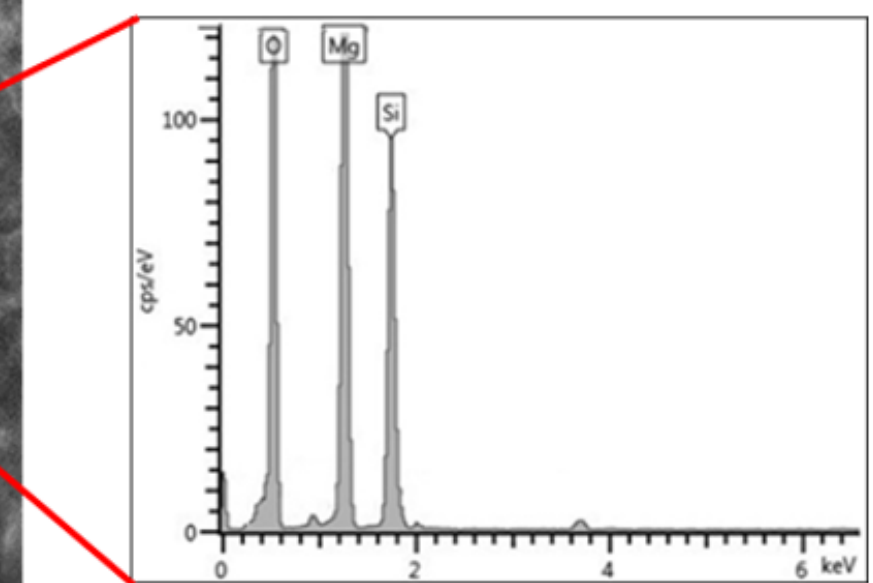

b

Figure 5

SEM image for FSpp (a), with 200 nm scale bar, coupled with EDX (b).
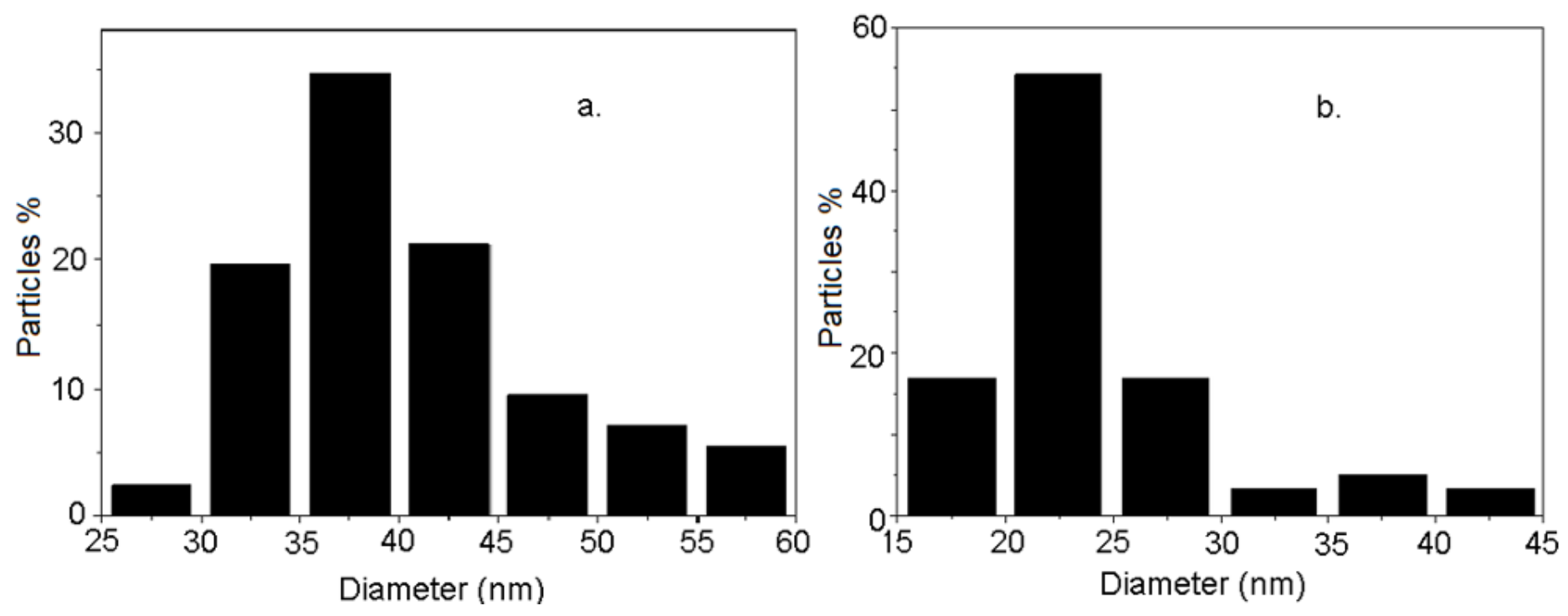

Figure 6

Histograms of particle-size distribution for FSsg (a) and FSpp (b). On the y-axis the particle fractions (in $\%)$ are represented versus their diameters in certain size ranges (i.e., as shown on the x-axis). 


\section{Figure 7}

AFM images for FSsg: a) 2D topography image, b) phase image, c) amplitude image, d) 3D image, and e) cross section profile on the arrow in image (a). Scanning area of $1 \mu \mathrm{m} \times 1 \mu \mathrm{m}$. Surface roughness about 2 $\mathrm{nm}$.

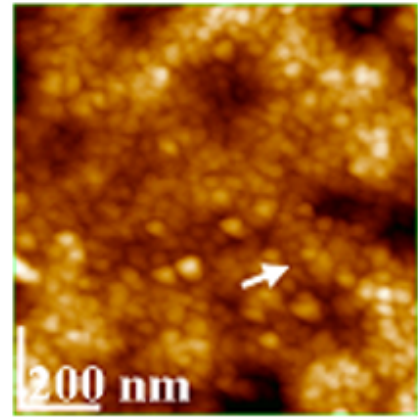

a

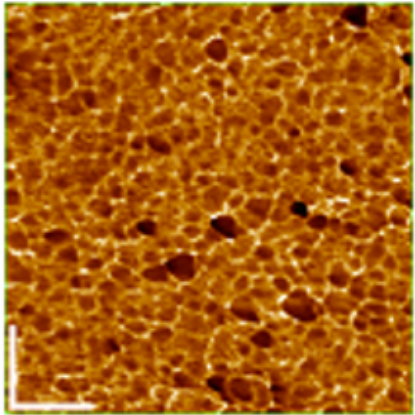

b

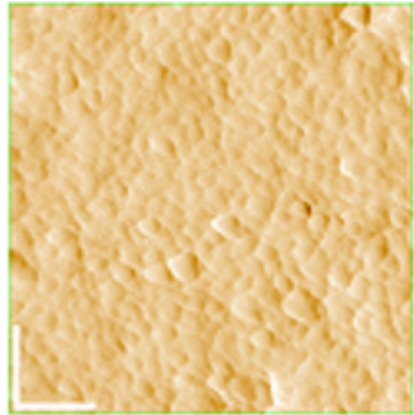

$\mathrm{C}$

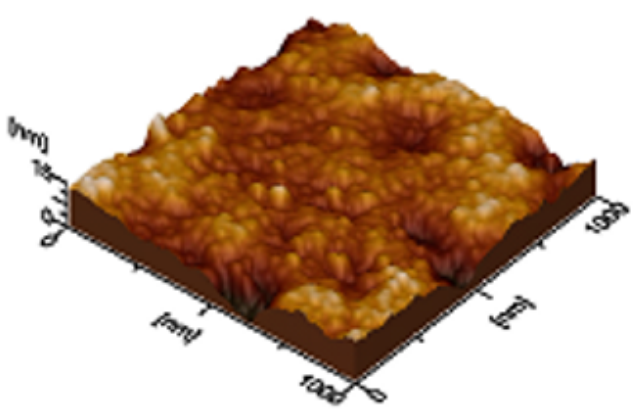

d

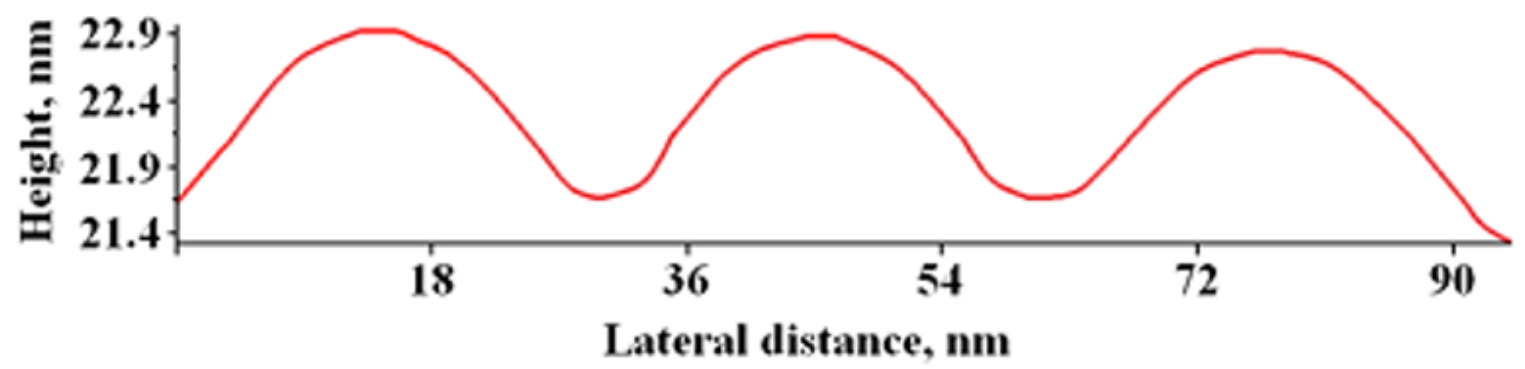

e

\section{Figure 8}

AFM images for FSpp: 2D topography image, b) phase image, c) amplitude image, d) 3D image, and e) cross section profile on the arrow in image (a); scanning area of $1 \mu \mathrm{m} \times 1 \mu \mathrm{m}$; surface roughness about 2 $\mathrm{nm}$. 


\section{Figure 9}

Antimicrobial testing for samples 1 (FSsg) given in panel (a) and 2 (FSpp) in (b) against Staphylococcus aureus: sectors: 1 for $10 \mathrm{mg} / \mathrm{mL} ; 2$ for $5 \mathrm{mg} / \mathrm{mL} ; 3$ for $2.5 \mathrm{mg} / \mathrm{mL} ; 4$ for $1.25 \mathrm{mg} / \mathrm{mL} ; 5$ for control (without forsterite).

\section{Figure 10}

Inhibitory effect of FSsg and FSpp on Staphylococcus aureus.

1 (FSsg): lack of inhibitory effect (colony development);

2 (FSpp): induction of the inhibitory effect (lack of colony development).

\section{Figure 11}

Inhibitory effect of FSsg and FSpp in nutrient broth tubes; 
1 (FSsg) - bacteria culture development (lack of inhibitory effect),

2 (FSpp) - lack of bacteria culture development (inhibitory effect).

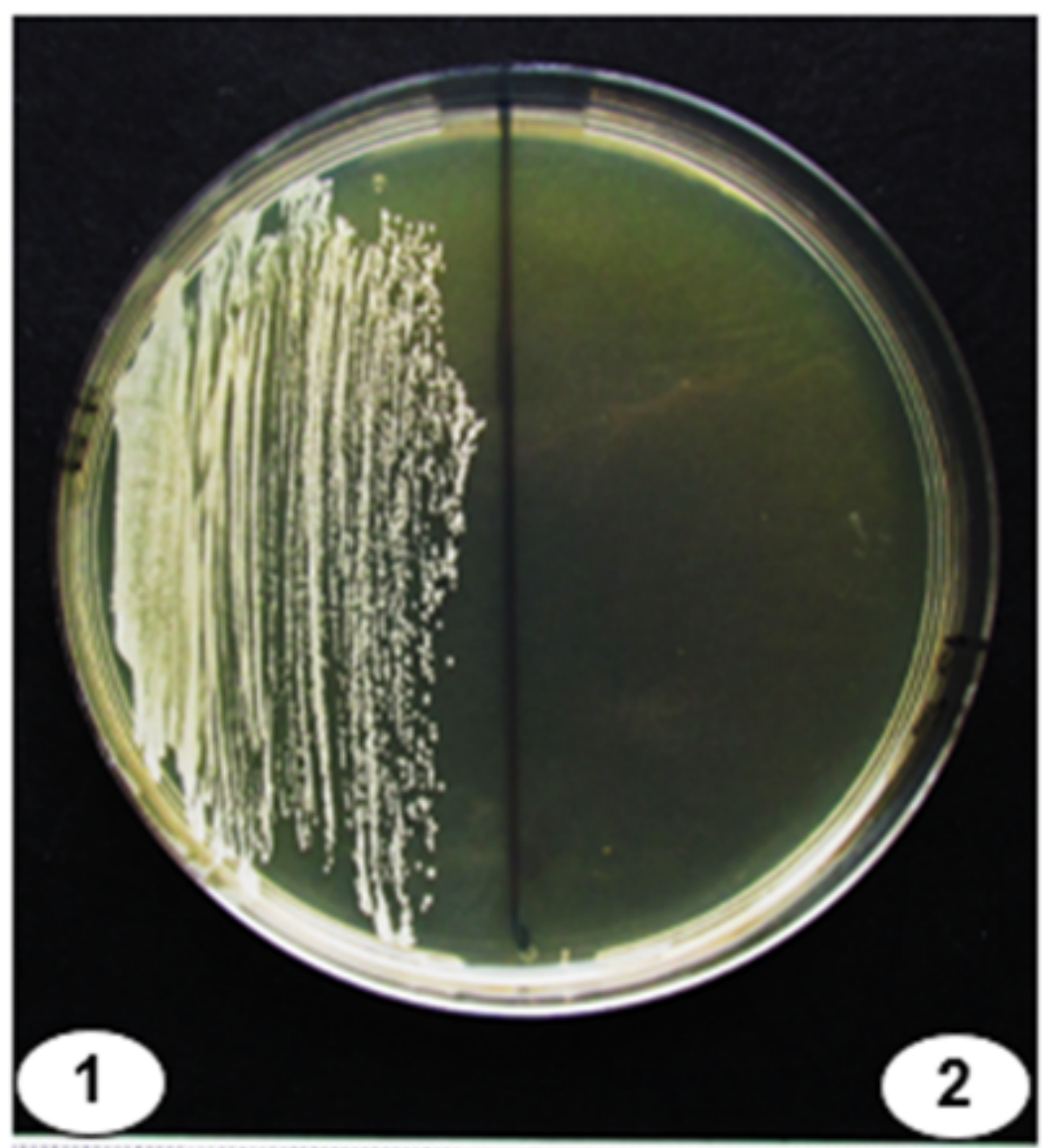

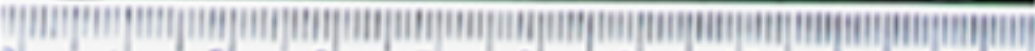

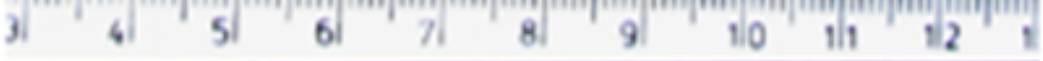

Staphylococcus aureus ATCC 6538 P

Figure 12

Checking the type of inhibition by agar plate inoculations;

1 (FSsg) with colony development (lack of inhibitory effect);

2 (FSpp) with lack of colony development (bactericidal effect). 


\section{Figure 13}

Antimicrobial testing for both samples: 1 (FSsg) in (a) and 2 (FSpp) in (b),

Against Staphylococcus aureus in relation to the contact time.

\section{Figure 14}

Antimicrobial testing (after $24 \mathrm{~h}$ of hydration) against Staphylococcus aureus;

1 (FSsg): lack of inhibitory effect (colony was development);

2 (FSpp): inhibitory effect (lack of colony development). 